\title{
Single-Flow System for Acid Hydrolysis and Base Condensation
}

\section{Key words}

acid hydrolysis

Henry reaction

Knoevenagel

reaction

mesoporous silica
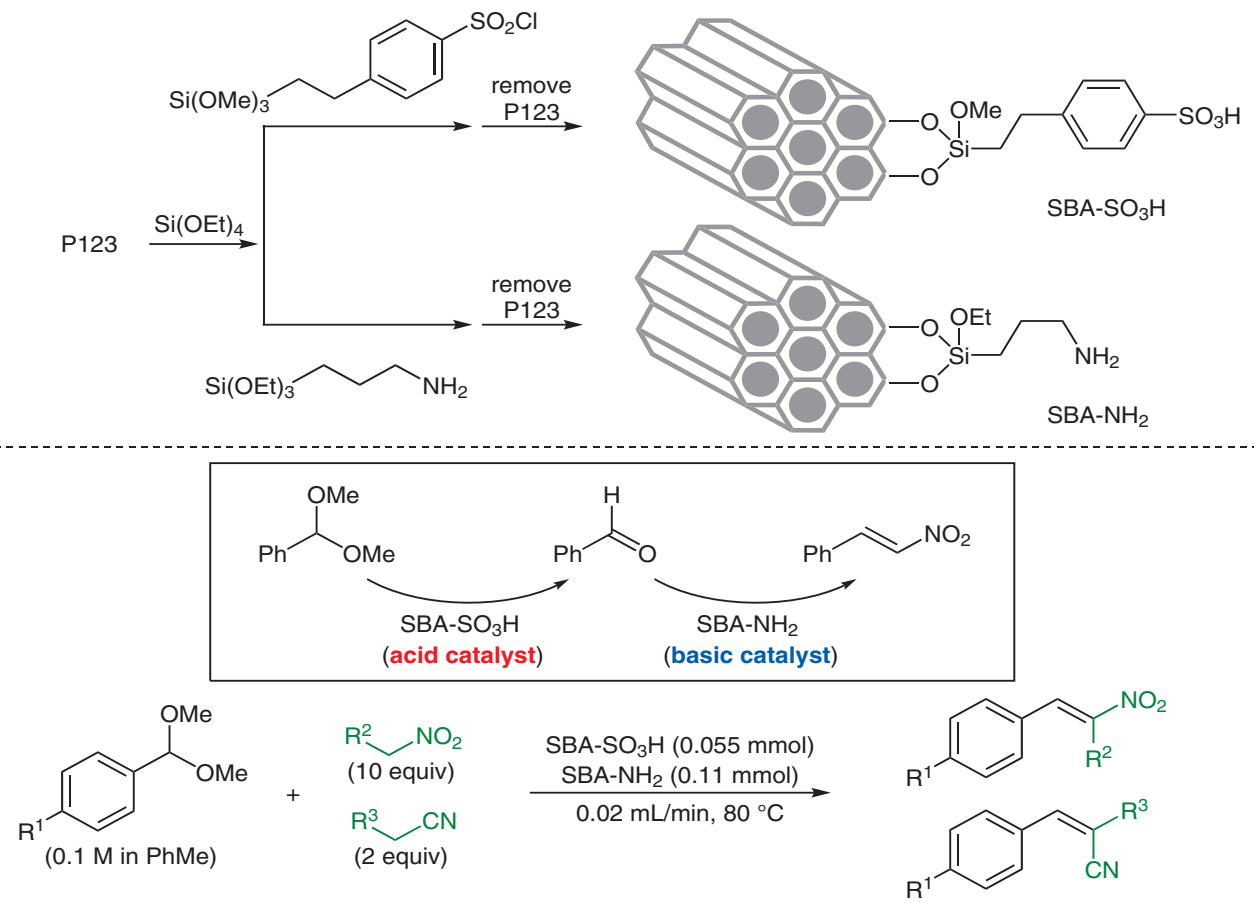

Selected results:
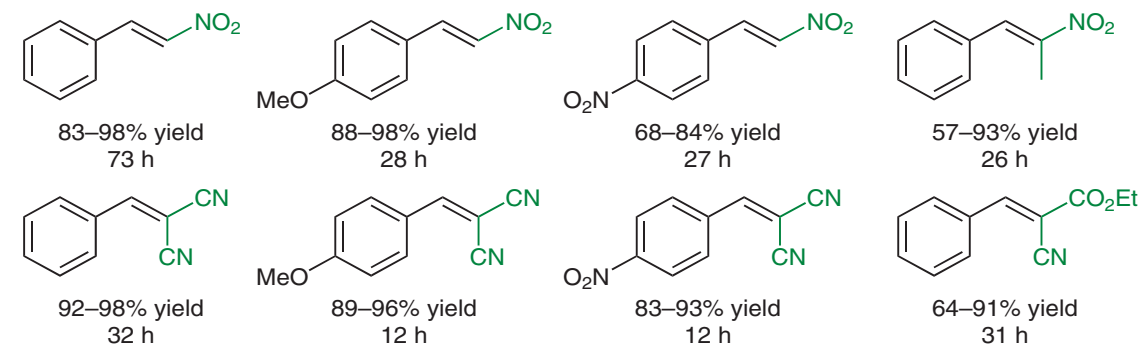

Significance: Two types of SBA-15-based mesoporous silica bearing sulfonic acid groups (SBA$\mathrm{SO}_{3} \mathrm{H}$ ) and amine groups (SBA- $\mathrm{NH}_{2}$ ), respectively, were prepared according to equation 1 . Acid hydrolysis of acetals and subsequent $\mathrm{C}-\mathrm{C}$ bond-forming condensation (i.e., a Henry reaction and a Knoevenagel reaction) were achieved in a flow system using a single packed-bed reactor charged with $\mathrm{SBA}-\mathrm{SO}_{3} \mathrm{H}$ and $\mathrm{SBA}-\mathrm{NH}_{2}$ (eq. 2).
Comment: $\mathrm{SBA}_{-} \mathrm{SO}_{3} \mathrm{H}$ and $\mathrm{SBA}-\mathrm{NH}_{2}$ were characterized by TEM, FT-IR, $\mathrm{N}_{2}$ adsorption and desorption, BET, TGA, and TPD analyses. The authors also prepared a catalyst functionalized with both $\mathrm{SO}_{3} \mathrm{H}$ and $\mathrm{NH}_{2}$ groups, $\mathrm{SBA}-\mathrm{SO}_{3} \mathrm{H} / \mathrm{NH}_{2}$, but its catalytic activity was inferior to that of a physical mixture of $\mathrm{SBA}-\mathrm{SO}_{3} \mathrm{H}$ and $\mathrm{SBA}-\mathrm{NH}_{2}$. 